\title{
Examples in Igbo-English Dictionaries
}

\author{
Mbanefo Chukwuogor \\ http://dx.doi./org/10.4314/ujah.v21i1.8
}

\begin{abstract}
A bilingual dictionary example is a verbal or non-verbal phrase or a grammatically complete sentence that includes the lemma and is translated from the source language to the target language or vice versa (Toope 1996). The use of examples in bilingual dictionaries has been an issue of discussion for many lexicographers like Al Kasimi (1977), Zofgen (1991), Jacobsen et al (1991), and Nielsen (2014) among others. This issue includes questions like 'What is an effective example?', 'Should examples be based on authentic material or should they be written (invented) by the lexicographer? This paper reviews metalexicographic literature on examples in bilingual dictionaries while focusing on two Igbo-English dictionaries with a view to finding out if certain considerations were taken into account in the use of examples. Consequently, it is observed that factors such as availability of space, dictionary type as well as idiosyncratic information, amount of information to be given and the need for generalization all influence the use of examples in both dictionaries thereby leading the researcher to conclude that the use of examples in Igbo-English dictionaries does not deviate but aligns with the norms reviewed in the literature.
\end{abstract}

Keywords: Bilingual Dictionary, Metalexicography, Lemma, Examples 


\section{Introduction}

Dictionary making consists of multiple stages of collecting and building data, deciding on the entry, defining the headwords, providing examples to illustrate the use of the words, etc. and each stage requires the presence of the compiler. It 'is not a theoretical exercise to increase the sum of human knowledge but practical work to put together text that people can understand' (Atkins \&Rundell 2008:6). While emphasizing the importance of examples, Sinclair (1987) expressed the thought that "a dictionary is nothing more than a commentary on the examples". Fontenelle (2008:9) observes that examples are a controversial component of dictionary entries which generate a lot of heated discussions among lexicographers. Some of the issues include whether the examples should be based on authentic material or should they be written (invented) by the lexicographer? If they are excerpted from a corpus, should they be left unchanged or is the lexicographer allowed to edit them? What is an effective example? These issues and more have been discussed with different views and opinions.

This paper deals on the use of examples in bilingual dictionaries while focusing on two (2) Igbo-English dictionaries with the aim of finding out how examples have been handled in Igbo lexicography. Subsequently, section two deals with the description of the term example and a review of existing literature on examples in dictionaries. Here, examples in both monolingual and bilingual dictionaries are discussed. In section three, we focus on the Igbo-English bilingual dictionaries with a view to understanding the types of examples used by the lexicographers as well as comparing the trend to what exists in the literature. Finally, the last section summarises and concludes the paper. 


\section{What are Examples?}

One type of lexicographical data that lexicographers can include in their dictionaries with a view to helping practitioners, researchers and translators communicate in a foreign language is often referred to as examples. A study of the existing literature reveals that the general term example is used in more than one sense. Svensén (2009:281) notes, that "in metalexicographic literature, the term example has a wide range of meaning. It usually comprises all types of indications consisting of word combinations (phrases, clauses, sentences) that contain a form of the lemma sign, irrespective of whether they are provided with an indication of meaning or not". Nielsen (2014: 200) notes that this description applies, in particular, to monolingual dictionaries, such as dictionaries intended for text production by foreign language users, though bilingual dictionaries with the same function may also contain lexicographical examples. He goes further to state that lexicographers often divide examples into different types. Zöfgen (1986 cited in Nielsen 2014: 200) proposes a classification based on the properties or characteristics of lemmas in monolingual dictionaries for learners such as, examples showing grammar data, collocations, clauses and phrases. Harras (1989 cited in Nielsen 2014: 200) distinguishes between syntactic data, collocations and sentences illustrating usage in monolingual dictionaries, among others. Furthermore, Bergenholtz (1995cited in Nielsen 2014: 200) discusses examples in specialised dictionaries and distinguishes between collocations, grammatical examples, citations, citation examples and competence examples; overall, he favours the use of example sentences. One reason for the different understandings of, and approaches to examples in dictionaries, appears to be the influence of linguistics and lexicology. Jacobsen et al (1991: 2784), who address examples in bilingual general dictionaries, 
suggest that examples should not be examined using a functional approach (understood as linguistic functions) but from a formal perspective (understood as components in dictionaries); in their words, an example in a dictionary cannot "be functionally defined in terms of the type of information it provides; it follows from this that it is not (meta)linguistically defined in terms of the linguistic categories (syntax, semantics, morphology) involved" (Jacobsen et al. 1991: 2784).Jacobsen et al (1991) give a detailed an insightful discussion of examples in bilingual dictionaries. Citing Zgusta (1971), Jacobsen et al (1991: 2783) states — about monolingual dictionaries - that "the purpose of the example is to show how the entry-word functions in combination with other lexical units"; and about the bilingual dictionary entry, he says that "there is a considerable amount of overlapping between glosses and examples" (Zgusta 1971 cited in Jacobsen et al 1991). On the nature of these examples, in contrast to other forms of explanatory matter in the dictionary, Jacobsen et al (1991) cite Bergenholtz (1984) who draws a useful distinction between explicit, halfexplicit and implicit information while noting that true examples obviously belong in the last category.

Additionally, they point out that Zöfgen (1986 cited in Jacobsen 1991: 2783), discussing monolingual learners' dictionaries, draws a distinction between made-up examples and authentic quotations - a distinction which they note is not very relevant for modern bilingual dictionaries. Furthermore, Zöfgen 1986 (cited in Jacobsen 1991: 2783) observes that using examples is the best way of throwing light on syntax. He suggests four (4) different ways in which this may be done: (a) by giving indications of grammatical properties, (b) through the use of collocations and (c) lemmatized collocations of high frequency, plus (d) by introducing clauses and phrases containing (a) + (b) or (c) as 
implicit information. He himself recognizes only (b) and (d) as true examples; for reasons that will appear we intend to be even more restrictive, recognizing only members of category (d) as examples. Jacobsen et al (1991: 2783) in agreement with Zöfgen (1986) note that the dictionaries themselves are not very helpful, and that most comments on "examples" in the prefaces to bilingual dictionaries are mere casual remarks. They go further to mention a few instances like the Svensk-engelsk Fackordbok (1977) that does not distinguish between examples and what it calls phrases. Gyldendal's small German Danish dictionary (= Gyldendalsblåordbøger T-D 1980) proposes using examples to indicate TL (target language) word-classes. VB (1976) uses the word eksempel both about SL (source language) - phrases to be illustrated and about asterisked TL-phrases without any SL equivalent, and uses the terms example and combination (of words) interchangeably. They observe that several other bilingual dictionaries that they examined do not comment on the category example at all and do not appear to have any clear conception of what examples are or ought to be. In their words, 'these are just some instances of the more general problem of terminology in bilingual lexicography' (Jacobsen et al 1991: 2783).

While arguing for a formal definition of the term example, Jacobsen et al (1991) give two major reasons in support of giving the term a formal definition: (1) The term has been used very loosely in the literature primarily due to its wide range of reference in normal language. They observe that, it is true, in a sense, to say that everything in a bilingual dictionary that is not the headword or explicit metalinguistic information exemplifies the use of the headword or its translation equivalents. Therefore, lexicographers tend to use example vaguely when referring to sub-entries (idioms, collocations and other syntagms with their translation equivalents). 
They admit that the situation is largely due to the historical dependence of bilingual dictionaries on the content and categories of monolingual dictionaries, in which there is considerably more justification for seeing sub-entries as exemplifications of the headword. 'In bilingual dictionaries, however, the majority of subentries provide one-to-one translation equivalents. They exemplify nothing.' (Jacobsen et al 1991). (2) Examples are multifunctional. Functionally, they overlap with many of the explicit categories of information provided in the entry (glosses, meaning discrimination, syntactic/stylistic/cultural/encyclopaedic information). In order to illustrate the differences between examples and other categories, Jacobsen et al (1991) use an extract from VB (1976) as shown below:

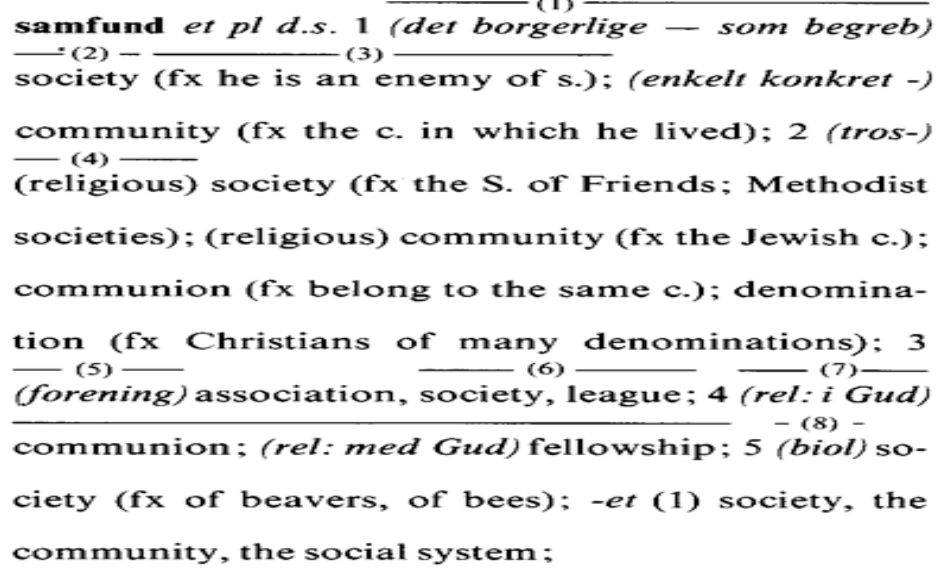

Dictionary entry from VB 1976 II., 270 cf. Jacobsen et al 1991:2784)

Based on the above excerpt, (Jacobsen et al 1991) assert that Item (1) has been called a gloss, a definition, meaning discrimination, an indicator, label, an explanation, etc. Item (2) is called a translation, an equivalent, and even a definition. Item (3) is termed 
as an illustration or an example. Item (4) we consider to be part of an equivalent, but it has also been called a type of gloss. A gloss is the term used to represent item (5) and all the other terms for Item (1) above, but it has also been called a synonym (as the word it contains can be regarded as a synonym of the headword). The words in Item (6) have also been called synonyms of the first equivalent. Item (7), a whole "sense" of the headword according to this dictionary, has been called a semantic subdivision, a subentry, a meaning, etc. Item (8) (biol, for "biological") has been called a gloss or a label. Furthermore, they reckon that a user who is not familiar with Danish may object that he or she is in no position to judge how many, if any, of these terms can reasonably be applied. Also, they state that large dictionaries will obviously have room for more examples than small ones.

Moreover, of equal importance is the type of dictionary involved. The distinction here is between active (encoding) and passive (decoding) dictionaries. At this point, it is prudent to mention that bilingual dictionaries are dictionaries which 'relate the vocabularies of two languages together by means of translation equivalents' (Hartmann \& James 1998:14). They are often based on one or several monolingual dictionaries. Consequently, bilingual dictionaries, which are discussed in this article, have a double function, since they can be used to serve either the decoding or the encoding function, and this is a point that should be taken into consideration when deciding what kind of examples to include in a dictionary. In practice, we do not have a set of four bilingual dictionaries to cover the vocabulary of two languages, while serving for either decoding or encoding by native speakers of either language. Consequently, it can be claimed that "bilingual dictionaries usually combine the features typical of both encoding and decoding dictionaries, which means that they can be referred 
to as combined encoding and decoding dictionaries" (Jacobsen et al. 1991: 2786). This is why bilingual dictionaries often include information the users do not need to comprehend a text in a foreign language or lack information the users would need to produce a text in a foreign language (Landau 2001: 307).

Jacobsen et al (1991) go a step further by outlining three interrelated factors a lexicographer must take into account when considering whether to use an example or one of the other formal lexicographical categories (sub-entry or gloss):

1. Degree of idiosyncrasy

2. Amount of information

3. "true" or "false" exemplification (basis for generalization)

The degree of idiosyncrasy of a syntagm can be seen as its position on a scale going from idioms where none of the elements are replaceable (once in a blue moon, which exhibits complete idiosyncrasy) through more flexible idioms (where, for example, syntactic features can be altered) via relatively frequent collocations to completely free syntagms (Pedersen 1986 cited in Jacobsen 1991:2787). On this issue, they note that a complete idiosyncratic syntagm is better presented as a sub-entry (sublemma + a translation equivalent which is as far as possible a corresponding fixed syntagm in the target language) than as an example.

The amount of information is a matter of how many features of the word or syntagm concerned can be conveyed by a well-chosen example compared with the space that wouldbe taken by an explicit formulation of these features. Examples, if judiciously selected, can demonstrate collocational, stylistic, syntactic, morphological, and cultural features of words and phrases. To show this, Jacobsen et al (1991) make use of a word 
from a Danish-English Dictionary. They note that "the Danish word dask is, among other things, a slang term for one Danish krone. If the relevant part of the entry on dask in a Danish-English dictionary reads: "dask[...] bob (fx it cost me ten bob)[...]" - the example tells the user that $b o b$ is used with numerals, that it has no $-s$ in the plural, and that it is used in a conversational context. This is of course reinforced by the fact that the Danish user knows how dask is used. A great deal of information is conveyed which would take up a lot of space if stated explicitly" (Jacobsen et al 1991: 2787).

The distinction between true and false examples is based on how far one can generalize from a given example. Jacobsen et al (1991) note that if they were to give s. v. ivrig in a Danish-English dictionary, the equivalent: "[...] avid (fx reader)[...]" we would be giving a "false" example. Reader is one of the few words (if not the only one) that can be used with an attributive avid. By giving an example of this form one is also giving the implicit information that the user is free to generalize.

So, they suggest that for practical reasons such as space, examples should be as few, as brief and as illustrative as possible. Furthermore, cultural distance between the languages involved also plays a role. A bilingual dictionary of languages from very different cultures will need many examples illustrating cultural/encyclopaedic factors, whereas if the non-linguistic background of the two languages is largely the same, fewer examples are needed.

Finally, having extensively discussed the issues surrounding the use of example in bilingual dictionaries, following Jacobsen et al (1991: 2784), we therefore define example as a supplement to a translation equivalent, providing implicit information about the equivalent or headword. To be even more 
precise, the example provides information about the equivalent insofar as it enters into the same range of contexts as the headword, while in some cases it provides information about the headword insofar as it can be translated by a given equivalent.

Having highlighted most of the major issues attached with the use of examples in bilingual dictionaries; the next section discusses the use of examples in Igbo-English dictionaries.

\section{Use of Examples in Igbo-English Dictionaries}

This section dwells on the use of examples in Igbo-English dictionaries. For this study, two dictionaries are examined: The Igbo-English Dictionary by Igwe (1999) and Echeruo (2001) IgboEnglish dictionary. The choice of both dictionaries is motivated by the fact that there are not many contemporary dictionaries in Igbo. Furthermore, of the few dictionaries that exist in the language, they are two of the most recent ones. In order to discuss the use of examples in both dictionaries, there is need to give some information about both dictionaries.

Igwe (1999) comprises 845 pages, whereas, Echeruo (2001) consists of 283 pages. Clearly, both dictionaries are not of the same size with Igwe (1999) being the larger dictionary with obviously more entries and possibly more examples. Echeruo (2001), while being an Igbo-English dictionary, also contains an English-Igbo index. This, in itself, represents a brief English-Igbo dictionary, in which the English equivalents of the headwords in the (main) dictionary are listed, and their Igbo equivalents provided. Igwe (1999) on the other hand does not have an EnglishIgbo part.

Before we look at actual examples used in both dictionaries, it is prudent to highlight the comments on examples in both dictionaries. Of course, the information on examples is 
situated in the introduction of both dictionaries. Echeruo (2001: xi) in a subsection explicitly dedicated to comments on examples, states that "as a matter of policy, examples have been provided only where they are absolutely necessary. Since the body of published material on which to base reliable citations of usage is relatively limited, ingenious examples created by the lexicographer can often become self-serving and unverifiable instruments. Such examples are avoided". In Igwe (1999), no separate subsection is given to comments on examples. However, examples are mentioned in a subsection on the entries. Here Igwe (1991: lvii) notes that "the infinitives of verbs are used in the examples, and both the entry and the examples are fully tone marked." He also indirectly mentions examples with the comment "personal and place names are not listed but occur in illustrative examples". So, the use of examples in Igwe's dictionary is implied whereas the use of examples in Echeruo's dictionary is explicitly stated. Since it has been made obvious that both dictionaries employ the use of examples, we shall set out to use some examples in both dictionaries in order to relate their usage to some of the issues raised in the literature.

To do this, we are going to use the factors from Jacobsen et al (1991) which must be taken into account when considering whether to use examples. They include:

(i) degree of idiosyncrasy

(ii) amount of information.

(iii) basis for exemplification

In addition, we are also going to take into consideration, the size of the dictionaries as well as the type of dictionaries involved. For this work, we shall follow Jacobsen et al's definition of examples as a supplement to a translation equivalent, providing implicit 
information about the equivalent or headword insofar as it enters into the same range of contexts as the headword, while in some cases it provides information about the headword insofar as it can be translated by a given equivalent. Hence, we shall not distinguish between examples, glosses, sub-lemmas and other related terms in the discussion of the Igbo-English dictionary examples.

1. Degree of Idiosyncrasy: As stated earlier, the degree of idiosyncrasy of a syntagm can be seen as its position on a scale ranging from idioms where none of the elements are replaceable through more flexible idioms to completely free syntagms. An excerpt from Echeruo (2001) below shows the entries cü̈ $v$ [HH] and cü̈aja $v$ [HH LL]

cü̈ $v[\mathrm{HH}]{ }^{1}$ drive out or away; expel, ${ }^{2}$ dismiss or terminate or sack (somebody), e.g. from appointment -cüöndiörü = sack workers; ward off; scare off - cüömmiri = ward off rain (through special powers).

cüöajav [HH LL] ${ }^{1}$ make sacrifice, either in person, or by proxy, through a priest; ${ }^{2}$ sacrifice something; give up some valued person or thing - jiri mä̈rü ma ndüyacüöaja = sacrificed both job and life; laid both work and life on the line. var. süöaja; tüöaja.

Dictionary excerpt 1: Dictionary entry (from Echeruo 2001:36)

From the entries above, a couple of observations can be made. First and foremost, there are two separate entries with each of the entries having their own separate examples. Furthermore, looking closely at the entries, a user of the dictionary who is familiar with 
Igbo will observe that both entries are indeed related even though this is not stated in the entries. The verb cüöin cüöajais used as an idiomatic expression. Jacobsen et al (1991:2787) recommend that a completely idiosyncratic syntagm is more suitable for presentation as a sub-entry (sub-lemma + a translation equivalent which is as far as possible a corresponding fixed syntagm in the TL) than as an example. But in the course of reviewing the literature, we note that even sub-entries are also examples. However, as shown in the excerpt above, the idiosyncratic counterpart of cüöis not presented as a sub-entry. Rather, it is presented as a separate entry that bears no relationship with the former.

2. Amount of information: The amount of information refers to how much information can be deduced from an example of choice in relation to the space that is available. We make use of two excerpts below to illustrate this point.

lï̈̈ $\quad v[\mathrm{HH}]{ }^{1}$ marry; wed - lïö di $=$ get married (for a woman); lüönwanyi = get married (for a man); ${ }^{2}$ secure a wife for somebody = lüölünwayanwunye $=$ secure (and/or pay all the bills to secure) a wife for his son; assume all the costs associated with son's marriage; 'be master of, dominate -nwanyïnaalü di ya $=a$ woman who runs her husband's life. var. löö; nüö.

Dictionary excerpt2: Dictionary entry (from Echeruo 2001:91)

From the above excerpt, we can clearly see that the entry lïo has the basic meaning of 'getting married'. However, more examples are given in order to show the cultural aspect of the entry. This is exhibited in the second sense "lüolünwayanwunye $=$ secure (and/or 
pay all the bills to secure) a wife for his son; assume all the costs associated with son's marriage'. Here, it is seen that marriage in Igbo culture bears certain unspecified costs. Furthermore, there exists the possibility of someone other than the future husband carrying the responsibility for the cost of the marriage rites. This information cannot be shown without the use of examples. Similarly, in a different dictionary, the entry also exhibits the same pattern of exemplification in order to show the cultural features of the entry as shown below:

lụv.t. marry, wed. (inf. Simple ịlụ̣; ger. inf. Ịlụ̂lụ)

ịlü di to marry a husband

ịlū nwaàny!̀ to marry a woman or wife

ịlụ nwunyè to marry a wife

ịlü kànwaàny İ/ nwunyèto treat as a woman or wife

ịlü nàchọọchị to marry in church

ilüjoto marry badly; not to take proper care of as wife or husband

Dictionary excerpt 3: Dictionary entry (from Igwe 1999: 373)

From the excerpt above, the verb 'lu (marry, wed)' has some examples which exhibit some cultural information. The use of 'ịlụnàchọọchị (to marry in church)' intended to show the dictionary user who is not familiar with Igbo culture, that the notion of 'marrying' has different types; notably the Christian marriage and the traditional marriage. Also worthy of note is the use of the example ilujjoto marry badly; not to take proper care of as wife or husband' which gives the user the idea that marriage in Igbo culture has certain standards and expectations. 
3. Basis for exemplification: As we have earlier shown, this relates to how far one can generalize from a given example. As we saw in the case of the Danish example, we also notice that this has criteria is also taken into consideration in use of some Igbo-English dictionary examples. In order to Illustrate this point, we use the entry abụ below:

abü $n$ [HL] (Önïca) hymn, psalm, song of joy, especially one associated with religious; the word of choice for the Protestant missions - Abï̈ma $=[$ Book of] Psalms; ndïabü = singers; musicians; choristers. var. ebu; avï. *See "ukwe"= hymn, the word favoured by the Catholic missions

Dictionary excerpt 4: Dictionary entry (from Echeruo 2001:4)

abụ̀ $n$. Church or Christian songs; hymn; anthem; (see ùkwe 1) abụ akw'āfuneral song, hymn, dirge (lit. crying, mourning song) abụ mbid'o/mmàliteopening hymn; introit;abụmgbasàclosing hymn; dismissing hymn;recessional hymn; abụ mmeritriumphal, victory hymn, song;abụ nchetaremembrance hymn;abụ och 'ièold hymn, song; old hymn book; a'ù òtùtòsong of praise; anthem;abụ ohụọnew song, hymn;Abù

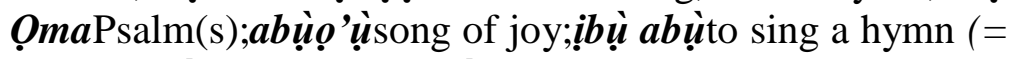
ig'ụ abụ̀ ); ikwēabụto sing antiphorically or responsively;ọbuabụ, òg 'uàbụ, òkweàbụ, okw'aàbụsinger

Dictionary excerpt 5: Dictionary entry (from Igwe 1999: 4) 
Based on the excerpts above, the use of the different examples for abù informs the dictionary user against making generalizations of the meaning and use of the word. Apparently, the word is related to religious services and this seems to be the major sense and usage of the word. However, the examples have been inserted in order to show the user that there are other possible usages as well as word combinations. Between both dictionaries, Igwe (1999) presents more examples on the entry than Echeruo (2001). This is mostly due to the size of both dictionaries with Igwe (1991) being four times larger than its counterpart. This also reminds us that these factors are really interrelated.

Also, there is the issue of the type of dictionaries involved. As we have seen, in the literature, the type of bilingual dictionaries (whether encoding or decoding) usually influences the type of examples that are provided. In the case of Echeruo (2001: vii), the lexicographer notes that 'because it was not conceived of as a "learner's dictionary", this volume has not tried specifically to find or provide Igbo equivalents for particular English words. Quite the reverse: the dictionary has tried to identify Igbo words and to provide an English-language gloss to those words in as approximate a sense as is possible. In consequence, users anxious to find Igbo equivalents for particular English words may have to turn to the English Igbo-Index for the closest synonym." From the above statement, it is clear that the dictionary is a combined encoding and decoding dictionary. Similarly, Igwe (1999: LVII) notes that the dictionary "is meant to be a scholarly and scientific book from which serious minded students of Igbo as well as teachers can find plenty of encouragement and help." Apparently, both dictionaries are not learner's dictionaries. However, unlike Echeruo (2001), Igwe (1999) is simply an encoding dictionary. Interestingly, Jacobsen et al (1991) suggests that "as for the large 
group of combined encoding and decoding dictionaries that exist in the real rather than the ideal world, they must be treated as encoding dictionaries, and be furnished with examples." Apparently, this seems to be the case in both bilingual dictionaries.

\section{Summary and Conclusion}

This paper started by introducing the term 'example'. In the literature review, it was observed that the term has a wide range of meaning and is usually confused with the term 'gloss'. Moreover, we noted that the cause of the confusion in terminology was due to the influence of monolingual lexicography on bilingual lexicography.

Furthermore, we looked at the different views of 'example' while noting that a proper definition of the term had to be formally based. In addition, following Jacobsen et al (1991) we outline the different interrelated factors that were responsible for the use of examples in bilingual dictionaries. We went ahead to relate these different factors in the literature to the two Igbo-English dictionaries under observation. Hence, it was observed that the different factors mentioned in the literature also came to play in the Igbo dictionaries. Firstly, examples were used to illustrate idiosyncratic syntagms like 'cüöaja' which was attested in the literature. Secondly, both dictionaries employ the use of examples to convey certain implicit information as in the case of 'lu/lü̈̈'. Also, examples are used in both dictionaries in order to avoid generalization of the meaning of the entries. This is shown in the case of 'abụ'.

Additionally, it was also observed that the size of the dictionaries to a large extent affects the use of examples. So, since Igwe (1999) is the larger of both dictionaries under study, it would definitely have more examples than Echeruo (2001) and vice versa. 
Seeing as both dictionaries are practically active or encoding dictionaries, the use of examples is reduced as the dictionaries go from the language of the user (Igbo in most cases) to the foreign language (English). Jacobsen et al (1991) note that such dictionaries do not need exemplification of the source language lemmas and sub-lemmas since the competent dictionary user may be able to furnish such examples himself. On this note, we opine that the use of examples in both Igbo-English dictionaries is similar to what exists in other languages and does not exhibit any peculiarities.

\section{Mbanefo Chukwuogor}

Department of Linguistics

Nnamdi Azikiwe University, Awka

mc.chukwuogor@unizik.edu.ng

\section{References}

Al-Kasimi, Ali M. (1977). Linguistics and Bilingual Dictionaries. Leiden: E.J. Brill.

Atkins, B. T. S. \& Rundell M. (2008). The Oxford Guide to Practical Lexicography Oxford: OxfordUniversity Press.

Echeruo. M. J. C. (2001). Igbo-English Dictionary: A Comprehensive Dictionary of Igbo Language with an English-Igbo index. Nigeria: Longman

Fontenelle, T. (Ed.) 2008. Practical Lexicography: A Reader. New York: Oxford University Press

Hartmann, R.R.K. \& JamesG. (1998). Dictionary of Lexicography. London: Routledge.

Igwe, E.G. (1973). Igbo-English Dictionary. Ibadan: University Press Plc. 
Jacobsen, J.R., Manley, J. and Pedersen,V.H. (1991). Examples in the Bilingual Dictionary. Hausmann, F.J. et al. (Eds.). 1991: 2782-2789.

Landau, S.I. (2001). Dictionaries: The Art and Craft of Lexicography. Second Edition. New York/Cambridge: Cambridge University Press.

Nielsen, S. (2014). Example Sentences in Bilingual Specialised Dictionaries Assisting Communication in a Foreign Language. Lexikos24: 198-213

Sinclair, J. M. (1987). The Dictionary of the Future. Collins English Dictionary Annual Lecture. University of Strathclyde, 6 of May 1987.

Svensén, B. (2009). A Handbook of Lexicography: The Theory and Practice of Dictionary-Making. Cam-bridge: Cambridge University Press.

Toope, M. (1996). Examples in the Bilingual Dictionary. Unpublished M.A. Thesis. Ottawa: University of Ottawa. [Online]. Available at: http://www.ruor.uottawa.ca/bitstream/10393/9942/1/ MM15769.PDF [28 January 2016].

Zöfgen, E. (1991). Bilingual Learner's Dictionaries. Hausmann, F.J. et al. (Eds.). 1991: 2888-2903. 